\title{
Single Stage Active Power Factor Correction Circuit for Street LED Light with Battery Backup ${ }^{\dagger}$
}

\author{
Asad Muneer*, Ahsan Fayyaz, Shahid Iqbal, Muhammad Waqas Jabbar, Arslan Qaisar and Faisal Farooq
}

check for

updates

Citation: Muneer, A.; Fayyaz, A.; Iqbal, S.; Jabbar, M.W.; Qaisar, A.; Farooq, F. Single Stage Active Power Factor Correction Circuit for Street LED Light with Battery Backup. Eng. Proc. 2021, 12, 69. https://doi.org/ 10.3390/engproc2021012069

Academic Editor: M. Jehanzeb Irshad Published: 4 January 2022

Publisher's Note: MDPI stays neutral with regard to jurisdictional claims in published maps and institutional affiliations.

Copyright: (C) 2022 by the authors. Licensee MDPI, Basel, Switzerland. This article is an open access article distributed under the terms and conditions of the Creative Commons Attribution (CC BY) license (https:// creativecommons.org/licenses/by/ $4.0 /)$.

\author{
Department of Electrical Engineering, Hafiz Hayat Campus, University of Gujrat, Gujrat 50700, Pakistan; \\ 18084422-006@uog.edu.pk (A.F.); si@uog.edu.pk (S.I.); waqas.jabbar@uog.edu.pk (M.W.J.); \\ 18103322-021@uog.edu.pk (A.Q.); 18103322-022@uog.edu.pk (F.F.) \\ * Correspondence: asad.muneer@uog.edu.pk \\ + Presented at the 1st International Conference on Energy, Power and Environment, Gujrat, Pakistan, \\ 11-12 November 2021.
}

\begin{abstract}
This paper introduces and uses a single-phase, high-power LED driver with a battery backup. The buck-boost converter and reverse converter are both combined to achieve optimal performance. In the first part of the integrated circuit, the buck-boost converter is simply used to adjust the power when operating in the non-continuous operating mode. The reverse converter provides free voltage to the LEDs when released as a remote DC-DC converter. The battery backup cycle directly charges the battery at the same power as the LED driver required and provides charging power when there is no electricity. This paper demonstrates the functionality of the entire system and proves that it is an effective solution for new lighting applications.
\end{abstract}

Keywords: converter; driver; light-emitting diode (LED); streetlight

\section{Introduction}

Light is necessary for humans to function properly. Without light, movement and many other activities would be tough. We are unable to see without light, and so it is the reason our sight developed. So, artificial light was developed to light up our indoor or dark places [1]. The efficiency of LED lights is high compared to other lighting methods. The theoretical lifetime of LED lights is $100,000 \mathrm{~h}$, which is ten times greater than the life of fluorescent lamps, while incandescent lamp and halogen lamps have much shorter life times of $4000 \mathrm{~h}$ and $6000 \mathrm{~h}$, respectively [2]. LEDs, compared to CFL, are free from mercury, which is dangerous not just for the environment but also for humans [3]. For HID lamps, a high voltage required, as long timeframe, going from the transient to steady state [4]. Therefore, LEDs are high in efficiency, small in size and environmentally friendly. The backbone of all facilities using a power supply is the electrical distribution system. A capacitor-input voltage filter is usually applied to derive DC voltage from an AC commercial power source, after a diode bridge rectifier. The input current pulsates with this filter and this pulsating current amplifies the reactive power and input current harmonics. Additionally, a highpower factor is needed to eliminate these. The power factor will increase by reducing the input current harmonics [5].

The future generation of light sources are LED lights, which are considered to be the best option for artificial light due to their better properties compared to traditional light sources. Vehicle lights, domestic lighting, decoration street lighting, LCD backlights and traffic signals are the major applications of LEDs. Power loss in lighting is a worldwide problem. The use of LEDs is reasonable, but power loss is still a problem in LEDs, reducing the battery backup and effect on efficiency. So, power loss from AC-to-DC conversion is a real problem for the battery back-up. Most of the lighting load is currently operating on $\mathrm{DC}$ rather than $\mathrm{AC}$ due to the worse cost effectiveness in electricity charges, but there is still too many power losses while converting AC to DC due to the low power factor [6]. So, 
the power factor is a major consideration and improvements in this aspect are necessary to mitigate power losses.

\section{Methodology}

The structure of the proposed circuit is presented in Figure 1. In the proposed circuit, first of all, an AC source provides an alternation current to four diodes, D1, D2, D3 and D4, which are joined in such a way to make the rectifier convert the alternating current coming from the power source to a pulsating DC. After this, an input filter is applied which eliminates high-frequency current harmonics to obtain the sinusoidal input current. Furthermore, a buck-boost converter is attached with a rectifier, and the pulsating DC is fed to the buck-boost converter, which has two switches, one capacitor, one inductor and one diode named S1, S2, Cdc, L and D5, respectively, where S1 and S2 are two MOSFET switches and Cdc is the DC link capacitor. Diode D5 activates for very short time. This buck-boost converter, which is integrated with a fly-back converter, carries out power factor correction. The power factor is corrected automatically due to this buck-boost converter stage. A fly-back converter has these components, a common switch (S2), a transformer (T1), a diode (D6), a common diode (D5) and an output capacitor (C0). The transformer has one primary and one secondary winding and an S2 switch is common for both converters; it reduces the size of the circuit. A current passes from the primary winding of the transformer and charges its core, which induces a secondary winding of transformer. This current will charge the output capacitor (Co). This fly-back DC-DC converter provides a steady ripple-free voltage to the output LEDs. A battery backup circuit is also integrated with an LED driver. A battery backup circuit is formed with a RC branch, two MOSFET switches, Q1 and Q2, and an RL branch.

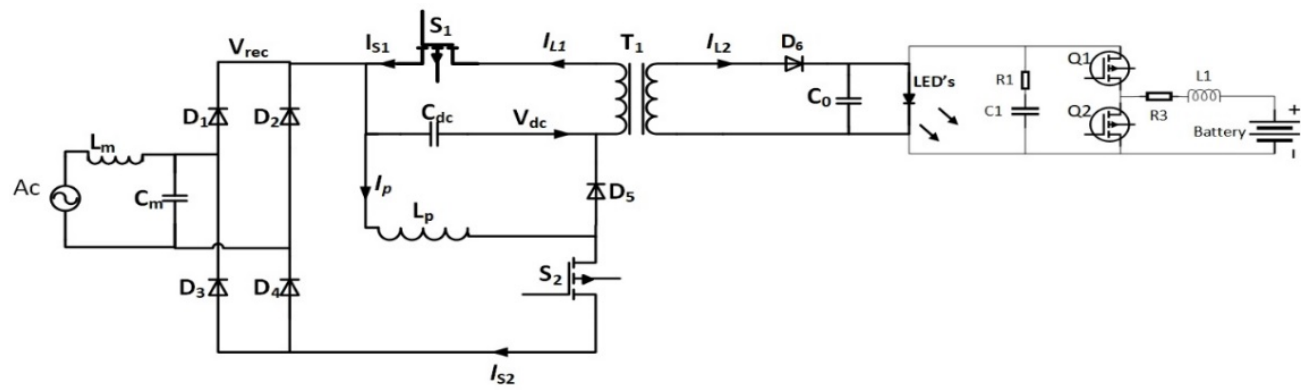

Figure 1. Proposed LED driver circuit.

LEDs need DC current for their operation but when we operate an LED on AC, then an AC-to-DC conversion circuit is required, but at the input a high current causes high harmonic distortion; for this reason, low-pass filter is applied as an input to solve this problem. Additionally, in the second part a bridge rectifier converts the AC power into a DC. In the third part, a buck-boost converter is used, which uses the rectified pulsating DC voltage, and the power factor is corrected naturally. In the next part of the circuit, a fly-back converter is used to smooth the DC link voltages and these regulated voltages are used to power the LEDs and charge the battery. Additionally, the last part of the circuit is the battery backup circuit which is a bidirectional converter and it facilitates the current flow in both directions (in the case of charging from source to battery and in the absence of a source from battery to LEDs).

\section{Implementation}

In this section, a detailed design of a long-life power factor-corrected LED driver for streetlight applications based on an integrated buck-boost converter and fly-back converter is presented. The proposed topology has few switching losses, high efficiency, low THD (good PFC) and low stress on switches. All the parameters and components of the proposed LED driver are precisely designed to achieve the above-mentioned attributes. The converter 
is designed for input voltages of $220 \mathrm{~V}$ AC to $240 \mathrm{~V} \mathrm{AC}$ and output voltages of $100 \mathrm{~V}$ DC to drive the LEDs.

To design the LED power factor correction driver, we should be aware of the requirements of our converter.

First of all, basic design requirements are needed to further the design procedure. The design procedure is summarized in Figure 2 (Flow chart). With the help of initial design specifications, first of all we selected the value of Lp (inductor) using the appropriate formula. The buck-boost converter switching period and value of the inductor are important for the output voltage.

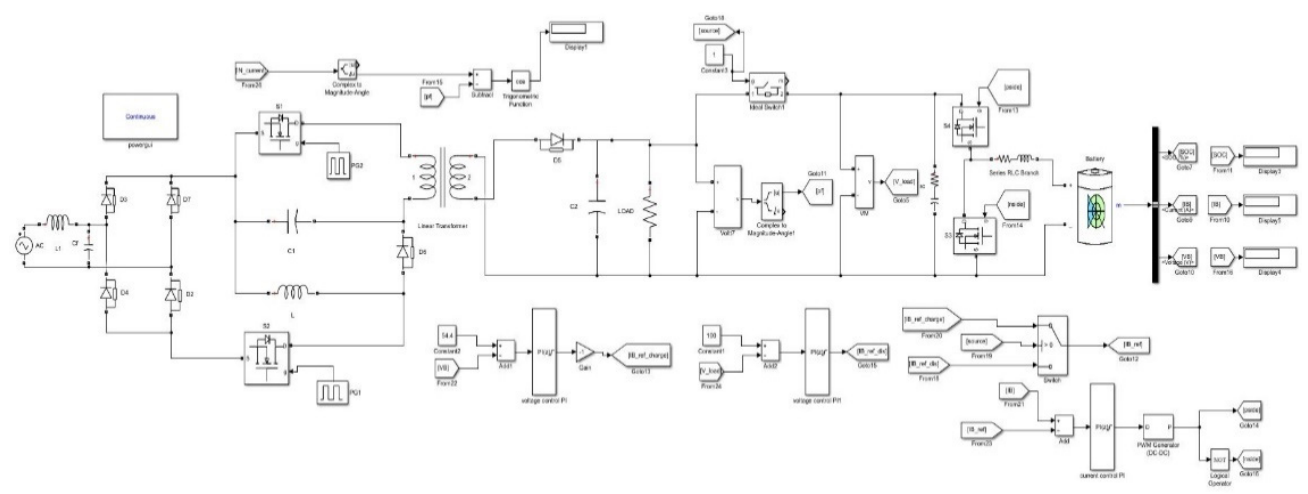

Figure 2. Simulation mode of proposed circuit.

\section{Results}

The proposed system is operated with a $230 \mathrm{~V}$ AC and $50 \mathrm{HZ}$ input and the output voltages are $60 \mathrm{~V}$ and output power is $100 \mathrm{~W}$. The proposed LED driver is simulated under different conditions, and its performance is monitored. Three cases are discussed: the first is when the input voltage is set to $230 \mathrm{~V} \mathrm{AC}$ as shown in Figure 3; the second case monitors the behavior of the circuit at low voltages $180 \mathrm{~V} \mathrm{AC}$ as shown in Figure 4 and in the third case the circuit operates at high voltages, $250 \mathrm{~V}$ AC as shown in Figure 5.

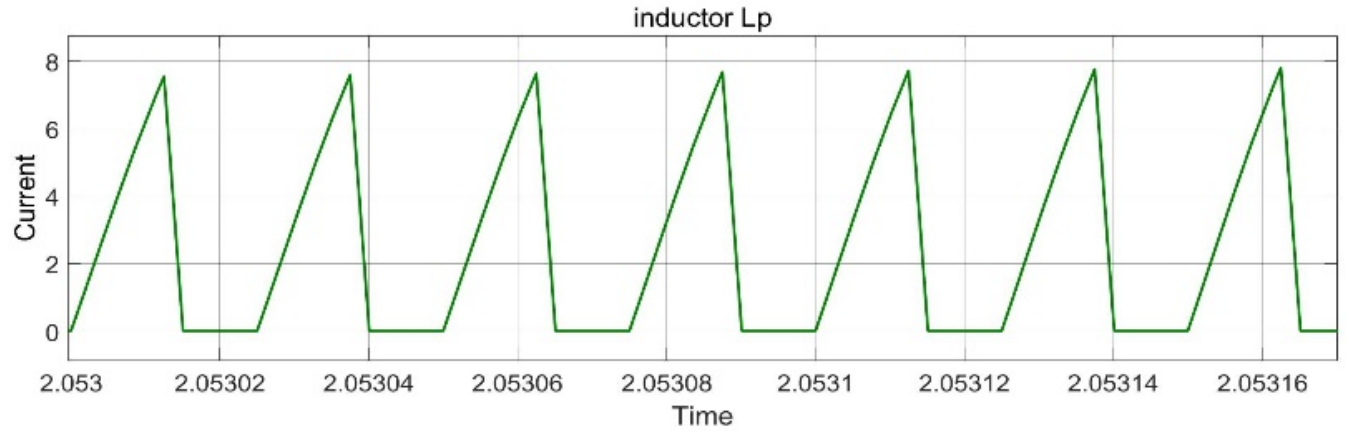

Figure 3. Circuit operation at $230 \mathrm{~V}$ AC.

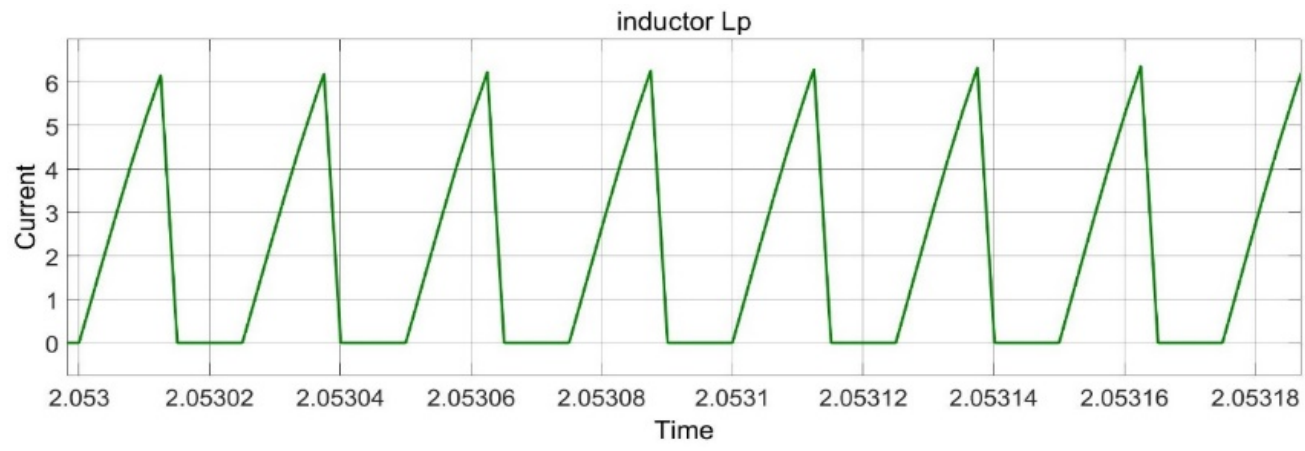

Figure 4. Circuit operation at $180 \mathrm{~V}$ AC. 


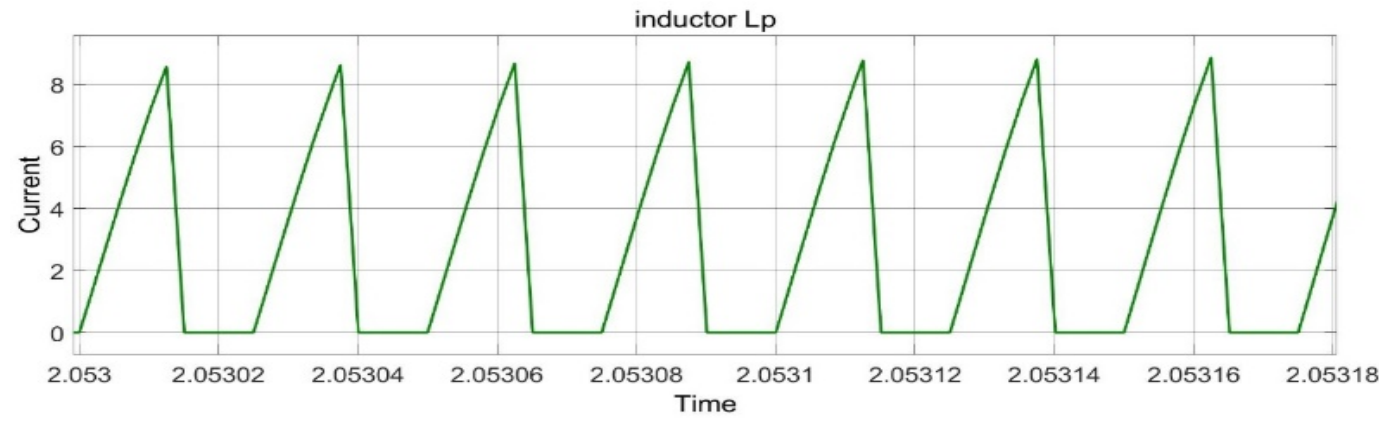

Figure 5. Circuit operation at $250 \mathrm{~V} \mathrm{AC}$.

The $L_{p}$ current rises when switch is on. The rate of the change of current shown in Figure 5 is too small, at $8.2 \mathrm{~A}$. The operation of the circuit is the same in this case as it is at normal voltage.

In this case, the buck-boost converter is also operated in the discontinuous conduction mode and the power factor is corrected.

\section{Conclusions}

This paper proposed a novel LED driver with a single-stage topology having two active switches. This circuit is run by the integration of the buck-boost and fly-back converters. The power factor correction is the main task which is carried out by the buck-boost converter and the buck-boost converter is designed to operate in the discontinuous conduction mode (DCM). The fly-back converter stabilizes the DC link voltages and provides this regulated voltage to LED stings which are placed in parallel. The simulation-based results show that the circuit performance is satisfactory. The measured power factor is 1 in the ideal simulation case and experimentally it should be 0.98 and the efficiency is 0.80 .

Funding: This work was supported by HEC-NRPU Project \# 8663.

Institutional Review Board Statement: Not applicable.

Informed Consent Statement: Not applicable.

Data Availability Statement: Not applicable.

Conflicts of Interest: The authors declare no conflict of interest.

\section{References}

1. Agamy, M.S.; Jain, P.K. A three-level resonant single-stage power factor correction converter: Analysis, design, and implementation. IEEE Trans. Ind. Electron. 2009, 56, 2095-2107. [CrossRef]

2. Alonso, J.M.; Viña, J.; Vaquero, D.G.; Martínez, G.; Osorio, R. Analysis and design of the integrated double buck-boost converter as a high-power-factor driver for power-led lamps. IEEE Trans. Ind. Electron. 2012, 59, 1689-1697. [CrossRef]

3. Arias, M.; Lamar, D.G.; Linera, F.F.; Balocco, D.; Aguissa Diallo, A.; Sebastián, J. Design of a soft-switching asymmetrical half-bridge converter as second stage of an LED driver for street lighting application. IEEE Trans. Power Electron. 2012, 27, 1608-1621. [CrossRef]

4. Athab, H.S.; Member, A.; Lu, D.D.; Member, S. A High-Efficiency AC/DC Converter With Quasi-Active Power Factor Correction. IEEE Trans. Power Electron. 2010, 25, 1103-1109. [CrossRef]

5. Chang, Y.-N. Self-Excited Single-Stage Power Factor Correction Driving Circuit for LED Lighting. J. Nanomater. 2014, $2014,107939$. [CrossRef]

6. Cheng, C.A.; Chang, C.H.; Cheng, H.L.; Chang, E.C.; Lai, C.C. A Novel LED Tube Lamp Driver with Power-Factor Correction for Indoor Lighting Applications. In Proceedings of the 2018 IEEE 7th Global Conference on Consumer Electronics, GCCE 2018, Nara, Japan, 9-12 October 2018; pp. 419-442. 